\title{
NOTAS PRÄTICAS
}

\section{CUIDADOS CINESIOTERÁPICOS NOS ACIDENTES VASCULARES AGUDOS CEREBRAIS}

\author{
Abrīo ANGHINAH *
}

Quando ocorre um icto, o importarite é salvar a vida do paciente. Entretanto, embora geralmente esquecidos, os cuidados cinesioterápicos são importantes e devem ser precocemente instituídos, acompanhando sempre a terapêutica medicamentosa, visando à profilaxia de seqüelas graves ou à rápida recuperação do paciente. Além disso, a mobilização precoce evita, em muitos casos, a formação de edema e trombose dos vasos nos membros inferiores, pois acredita-se que êstes distürbios sejam devidos à falta de contração muscular, dificultando a circulação de retôrno; evita-se, também, a dor articular decorrente da imobilidade e que propicia a instalação de periartrite por desuso.

De acôrdo com a maioria dos autores, a cinesioterapia deve ser iniciada 2 a 3 dias após o icto não hemorrágico e, nos hemorrágicos, logo após revelar-se normal o líqüido cefalorraquidiano. Entretanto, não só êste exame deve orientar o início da cinesioterapia: o estado geral e a idade do paciente, as condições cardiocirculatórias e a evolução pós-icto são fatôres que devem ser levados em consideração. Não resta dúvida que é preferível iniciá-la mais precocemente em pacientes jovens em bom estado geral do que naqueles com mais de 60 anos, em estado geral de regular para mau. Deve ter-se em mente que, muitas vêzes, o icto ocorre após enfarte do miocárdio e o paciente, 5 ou 10 dias após, ainda sente dôres precordiais com irradiação para o ombro; além disso, nos pacientes com angiosclerose generalizada, a tromboflebite do membro inferior paralisado não é incomum. Essas dôres podem confundir-se com as da periartrite (do ombro e coxofemoral), comuns nas hemiplegias com algum tempo de evolução e mais raras após o icto. Em pacientes cardiopatas pode desenvolver-se, após o icto, insuficiência cardiaca grave que deve ser imediatamente combatida. Nestas eventualidades o repouso deverá ser prolongado e alguns cuidados cinesioterápicos serão retardados.

Trabalho da Clinica Neurológica da Fac. Med. da Univ. de São Paulo (Prof. A. Tolosa).

* Assistente extranumerário. 
De acôrdo com a evolução, pođem ser consideradas as seguintes eventualidades: a) retôrno espontâneo e integral da linguagem e motricidade, 1 a 15 dias após o icto; b) distúrbios da linguagem com recuperação integral da motricidade, de modo mais ou menos rápido; c) normalização da linguagem sem recôbro da motricidade. Nestes dois últimos grupos podem ser enquadrados todos os tipos de seqüelas, devendo cada paciente ser analisado de per si.

O edema cerebral que se instala após o icto pode reabsorver-se paulatinamente e haverá recuperação gradual e total, ou então, devido à compressão, a célula nervosa é traumatizada e destruída, libertando-se outros sistemas motores. As lesões do sistema nervoso motor central (pirâmido-extrapiramidal) diferem quando se considera os sinais deficitários e os de libertação e, conseqüentemente, as seqüelas são variáveis. Geralmente a paralisia prevalece nas extremidađes quando há predomínio da lesão piramidal e atinge de forma mais acentuada as grandes articulaçōes quando prepondera a lesão do extrapiramidal. Dos sinais de libertação, tem importância, do ponto de vista cinético, a hipertonia, que será predominantemente seletiva e elástica nas lesões piramidais e será, nas lesões extrapiramidais, do tipo plástico, atingindo a musculatura em geral, num ou mais segmentos.

De uma forma ou de outra, o que ocorre comumente é que, durante a fase aguda, os músculos nos segmentos atingidos se apresentam sem qualquer sinal de contração e flácidos. Durante a fase de libertação (dias ou semanas após), instala-se a rigidez (extrapiramidal), ou então há evolução para a fase espástica (piramidal), que podem aparecer até 6 meses após. Só em raríssimos casos não há fase de hipertonia e o paciente se recupera totalmente.

O programa cinético a ser observado na fase aguda compreende: A) Manutenção de atitudes fisiológicas; B) Mudanças de decúbito; C) Mobilização passiva relaxada.

\section{A) Manutenção de atitudes fisiológicas.}

Recordando que a hipertonia (piramidal) é de tipo seletivo e elástico e que, após a fase flácida, os membros do hemicorpo atingido tendem a assumir a atitude de Wernicke-Mann*, cuidados deverão ser tomados, a fim de manter os segmentos atingidos em atitudes fisiológicas. As atitudes a serem mantidas na fase flácida, com o paciente em decúbito dorsal, serão:

1) Membro superior: um travesseiro colocado entre a face lateral do tórax e o braço mantém êste em abdução; a extensão e a supinação do ante-

* No membro superior a hipertonia atinge os adutores e rotadores internos do braço, flexores e pronadores do antebraço, flexores do punho e dos dedos; no membro inferior, são atingidos os extensores, rotadores externos e abdutores da coxa, extensores da perna, extensores e invertores do pé. Só em rarissimos casos a hipertonia atinge os flexores da coxa e perna. 
braço serão mantidas com um pequeno travesseiro ao nivel do cotovelo e um saco de areia ( 2 a $3 \mathrm{~kg}$ ), fazendo pressão na face anterior e têrço inferior do antebraço; os dedos em extensão serão mantidos com talas ou goteiras.
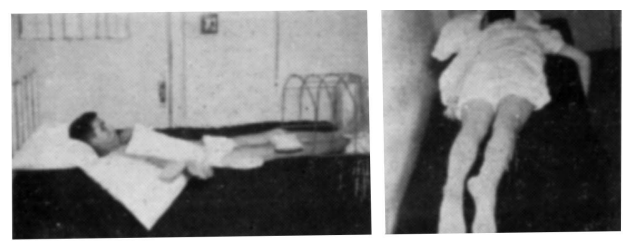

Fig. 1 - Atitudes fisiológicas nos decúbitos dorsal e ventral.

O membro superior, assim mantido, será elevado a uma altura de cêrca de $30 \mathrm{~cm}$ acima do nivel do leito, visando à melhor circulação de retôrno e prevenindo a formação de edema e cianose na mão (figs. 1, 2 e 3). Se o paciente estiver consciente poderá, com auxilio do membro superior são, man-
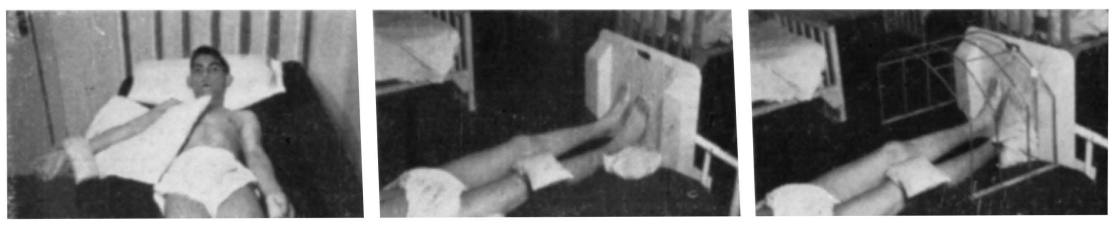

Fig. 2 - Manutençāo das atitudes dos membros superior e inferior do lado hemiplégico.
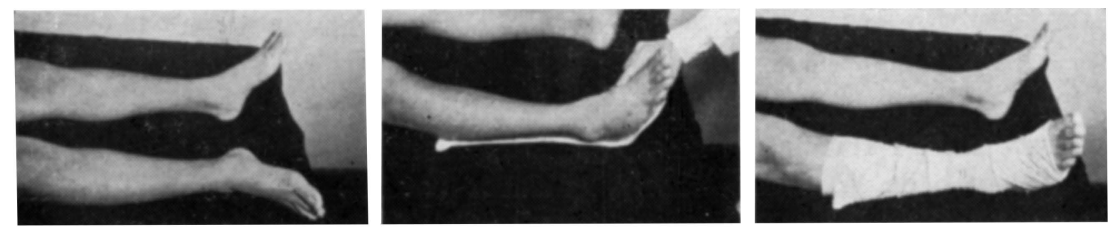

Fig. 3 - Fixação do pé em eversão e flexão de 90\%, por meio de goteira.

ter atitude útil, que impeça a formação dêste edema; êle poderá cruzar os dedos e levar as mãos para trás da nuca, ou então, segurar a mão doente prêsa à borda superior da cabeceira do leito (fig. 4).

2) Membro inferior: será mantido em extensão, adução e ligeira rotação interna, por meio de sacos de areia colocados na face lateral da côxa e sôbre o joelho; o pé apoiado em tábua colocada nos pés da cama e com um saco 
de areia no bordo lateral, evitando rotação e queda do pé para fora (pé de cadáver). O pé poderá ainda ser mantido por goteiras que o fixam em eversão e flexão até $90^{\circ}$ (figs. 2 e 3 ).
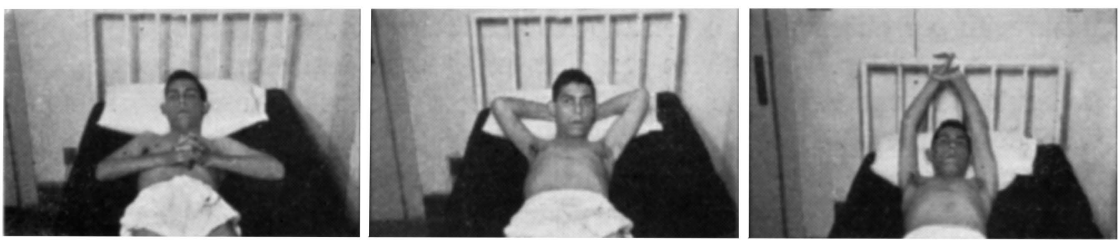

Fig. 4 - Atitudes do membro superior mantidas pelo paciente com auxilio do lado são.

Os membros serão assim mantidos durante 2 a 3 horas, quando então o paciente será subetido a mudança de decúbito.

\section{B) Mudanças de decúbito.}

Devem ser executadas de 3 em 3 horas durante o dia e de 4 em 4 horas durante a noite, evitando-se o decúbito ventral enquanto persistir o estado de coma. Os pacientes, ao recobrarem a consciência, serão instruídos a fim de executarem sòzinhos as mudanças de decúbito, utilizando-se dos membros do lado são. Nas primeiras duas semanas é prudente evitar o decúbito la-
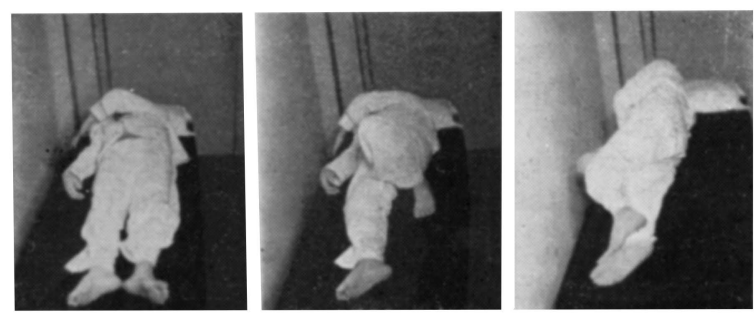

Fig. 5 - Mudança de decúbito executada pelo paciente.

teral no lado hemiplégico, pois que é mais sujeito à formação de escaras. No início, farão de cinco a 10 mudanças, duas vêzes ao dia, sendo as outras vêzes auxiliadas pela enfermagem ou pelos familiares. Progressivamente êste auxilio será dispensado pelo paciente (fig. 5). Evita-se dêsse modo a pressão das regiōes sacro-ilíacas de encontro ao leito e a formação de escaras de decúbito que, quando sujas por urina e fezes (ótimos meios de cultura), se infectam e aprofundam, atingindo, não raras vêzes, o plano ósseo. 


\section{C) Mobilização passiva relaxada.}

Praticada pelo técnico em fisioterapia, enfermeira ou pessoa da família devidamente instruída. Pode ser praticada pelo paciente no membro superior com auxílio do membro simétrico são.

Deverão ser observados o sentido de deslocamento, amplitude, ritmo e número de movimentos. Os vários sentidos em que se deslocam fisiològicamente as articulações encontram-se descritos nos compêndios de anatomia. A amplitude de cada movimento não poderá deixar de ser atingida, pois que deixar-se-á de exercer a tração necessária para manter a elasticidade da fibra e não poderá ser ultrapassada, pois pode ser sobrepujado o limiar de elasticidade, rompendo-se a fibra muscular. O ritmo deverá ser harmônico, para que o estímulo próprioceptivo seja transmitido de modo uniforme.

A mobilização será executada duas vêzes ao dia (entre uma e outra mudança de decúbito), sendo de 10 a 15 o número de movimentos em cada sentido.

Dêste modo os reflexos próprioceptivos despertam a consciência do movimento; a circulação de retôrno é favorecida; a elasticidade da fibra é conservada; e - o que é mais importante - - mantém-se a independência dos vários planos tissulares, o que previne a instalação de periartrites.

São contra-indicados nestes casos a massagem e os estímulos elétricos (sob qualquer forma), pois, em se tratando de lesão do sistema nervoso motor central, é poupada a célula motora do corno anterior, que é o centro trófico. Portanto, não há atrofia de músculos nestes pacientes; muito pelo contrário, há libertação dos sistemas motores inferiores e dos centros tonígenos. Só em pacientes que, em virtude de paralisia cerebral (forma hemiplégica), ficam sem usar os membros do lado lesado por vários anos é que se instala hipotrofia ou atrofia muscular de desuso.

Nos pacientes portadores de angiesclerose, acamados durante 2 a 3 meses, cuidados devem ser tomados em relação à movimentação passiva e mudanças de decúbito, pois que, dos vasos do membro inferior podem destacar-se trombos que podem obstruir vasos sangüíneos de outros órgãos, tais como a mesentérica (enfarte do intestino) ou vasos do pulmão (enfarte pulmonar).

A evolução da moléstia, na grande maioria dos casos será para a fase de libertação pirâmido-extrapiramidal, com predomínio de um ou outro sistema motor. Isto nos colocará frente a seqüelas motoras variáveis, cujos cuidados cinesioterápicos serão objeto de próxima publicação. 